\title{
Diários de aula como deflagrador de uma pesquisa Com experimentações audiovisuais
}

Lesson diary as boost for a research with audiovisual experiments

Lara Lima Satleri

Universidade Federal de Goiás

\section{Resumo}

Este artigo parte de experimentações audiovisuais que, registradas em diários de aula, deflagram uma pesquisa situada no campo da educação da cultura visual. Nesse sentido, a reflexão a partir dos diários de aula dos discentes e o meu detonam processos reflexivos sobre minha prática docente. Como professora-pesquisadora, eles provocam a sistematização das ideias para a construção de um percurso teórico-metodológico, culminando em uma pesquisa de doutorado, resumida neste artigo. Como a experimentação audiovisual associada ao uso de diários de aula podem deflagrar processos de pesquisa envolvendo a categoria professor-pesquisador? Por meio da análise de diários de aula dos participantes dessas experimentações audiovisuais, o texto objetiva discutir sobre o potencial deflagrador de reflexão sistemática da ferramenta. Como resultados, pretendo contribuir com pesquisas que utilizam diários de aula no campo da educação da cultura visual.

Palavras-chave: diários de aula, educação, cultura visual

\begin{abstract}
This paper results from audiovideo experimentations which, registrerd in lesson diaries, boost a research in the field of visual culture education. In this sense, the reflection upon the students' and my lesson diaries start reflective processes on my teaching practice. As a teacher-researcher, they provoke the systematization of ideas to the construction of a theoretical-methodological path, culminating in a PhD research, summarized in this article. How can an audiovisual experimentation associated to the use of lesson diaries deflagrate research processes involving the category teacher-researcher? By means of an analysis of the participants' lesson diaries in these audiovisual experimentations the text aims at discussing about the boosting potential for systemic reflection of this tool. As results, I aim to contribute with research that use lesson diaries in the field of visual culture education.
\end{abstract}

Keywords: lesson diaries, education, visual culture 


\section{Construir outros caminhos formativos}

A necessidade de refletir sobre minha ação docente tornou-se urgente, dentre outros aspectos, quando em 2009 um grupo de alunos/as de um curso de Comunicação Social Publicidade e Propaganda procurou a mim e a uma colega de docência para desabafar. Suas inquietações dialogavam muito com as minhas, quando eu era estudante. Entre elas lembro-me que os/as perturbava uma única ênfase do curso nas aulas em geral, pois, segundo eles/as, a maioria dos exemplos e exercícios tratava de agência de publicidade, em um sentido tradicional, clássico. Como se um curso de quatro anos estivesse os/as preparando para atuar somente neste espaço.

Do jeito que conseguiam, estes/as alunos/as reclamavam de certa estreiteza no modo de compreender uma formação, que poderia ser, na opinião deles, mais rica e desafiadora. Alguns queriam saber sobre a profissão, mas considerando outros possíveis espaços em que pudessem atuar depois de formados/as. Que espaços são esses? Como eles se constituem? Em quais formatos? É possível sobreviver financeiramente no interior do Brasil desses outros espaços?

Havia ainda os/as que se interessavam por saberes menos vinculados a uma urgência do mundo do trabalho como aqueles/as que requeriam conhecer sobre distintas imagens de arte, filmes e vídeos, suas curiosidades, suas origens, possíveis interpretações, etc. Mas não apenas interpretá-las ou conversar sobre elas, eles/as reclamavam experimentar técnicas, pondo a mão na massa, não apenas para aplicá-las profissionalmente de modo imediato, mas pela descoberta em si mesma.

Lembro-me ainda daqueles/as que tinham uma preocupação ética acentuada, sentiam-se de algum modo culpados pela escolha da publicidade como curso e profissão, pois leram aqui e ouviram acolá sobre os estragos sociais e psicológicos que o marketing e a publicidade teriam trazido para nossos dias. Sempre vinculados a uma crítica ao capitalismo, tais argumentos os/as incomodavam a ponto de evitarem proximidade e diálogos com estudantes do prédio ao lado, do curso de Ciências Socais.

De modo geral, estes/as estudantes tinham em mente que a universidade thes traria mais do que uma formação tão focada na concretude do trabalho, queriam saber sobre outros assuntos, sejam do âmbito da profissão e seus limites éticos, sejam de uma cultura de artefatos em geral. Além disso, argumentavam que um curso de quatro anos, oito semestres, não se justificava para que aprendessem apenas a trabalhar de um mesmo modo, em um mesmo espaço.

Com esse grupo a conversa se mostrou profícua e contínua. Num primeiro momento, foi necessário aglutinar tantos interesses, dialogando sobre o que era possível 
naquele momento e entre nós pensar. Aos poucos fui compreendendo que em parte o desabafo traduzia uma fragilidade curricular, em parte uma compreensão sobre o papel de um curso de Comunicação Social - Publicidade e Propaganda e também sobre o sentido do ensino superior nos tempos atuais.

Mas não era apenas isso. Contudo, me faltavam elementos para compreender o que mais podia ser. Por isso, pensar sobre este ensino foi se tornando gradualmente necessário. Iniciei assistematicamente uma pesquisa sobre como o curso de Comunicação Social - Publicidade e Propaganda fora criado no Brasil a fim de compreender se e como o passado histórico ecoa no contemporâneo.

Descobri, por exemplo, que a primeira ideia de formação em publicidade no Brasil ocorreu dentro da multinacional General Motors, a partir de 1926, diante da necessidade de qualificar mão de obra internamente para a divulgação das suas instalações no país ${ }^{1}$. Outra experimentação formativa ocorreu dentro do Museu de Arte Moderna (MAM), em 1951, ainda de modo a qualificar especialmente os futuros trabalhadores de departamentos de criação das agências. Tal experimentação formativa se tornou a Escola Superior de Propaganda de São Paulo (ESP), em 1961.

Mas ainda não se tratavam de cursos universitários, sendo categorizados como cursos livres. O primeiro curso universitário surgiu em 1978, a partir desta última experiência. Para construir seu currículo o curso se pautou tanto nestas experiências citadas, quanto nas demais habilitações da Comunicação Social, dentro e fora do Brasil.

Como mencionei, tal investigação foi isolada e assistemática. Atropelada pelos interesses deste grupo de alunos/as e por uma necessidade de formação em pesquisa, fui cuidar do urgente. E o que urgia? Conciliar tantos interesses e tão diversos para, pelo menos em relação àquele grupo construir outros caminhos formativos.

No primeiro momento, aqueles que se interessavam por imagens e experimentações tiveram mais voz e, por isso, criamos um projeto de extensão para abarcar um cine clube, que funcionaria no prédio da própria faculdade, após as aulas. A proposta era assistirmos a um filme e o debatermos semanalmente. Com o passar dos encontros, o grupo sentiu necessidade de leitura para aprimorar o debate e para ampliar a capacidade interpretativa das obras. Em grupo decidimos adotar o livro História do cinema mundial (MASCARELLO, 2009) a fim de ler um capítulo por semana e assistir um filme referente a cada um dos principais movimentos da narrativa cinematográfica internacional.

\footnotetext{
${ }^{1}$ Conferir em Satler (2010).
} 
Tão logo começamos, a proposta mostrou-se hercúlea. Além de esbarrarmos nas mesmas dificuldades encontradas no dia a dia das aulas, a falta de tempo para as leituras (ainda mais sendo extra), a pouca estrutura de exibição (numa semana não tinha sala, na outra o equipamento falhava, a chave da melhor sala tinha que ser entregue antes da secretaria fechar já que no prédio não havia atividades noturnas, etc.), e ainda o cansaço e a fome após quatro horas/aula foram fatores que tornaram inalcançável a linearidade do panorama horizontal da cinematografia internacional.

Em grupo, decidimos intercalar a proposta acima com experimentações, envolvendo o estudo sobre as tecnologias, o funcionamento e as linguagens das pioneiras máquinas de imagens em movimento, que culminou na exposição Sai da Caixa!, em maio de $2010^{2}$. Tal experiência gerou em mim a urgência de refletir sobre as suas variáveis, exigindo mais saberes sobre ensino e sobre pesquisa com imagens em movimento. Nesse percurso encontro a educação da cultura visual como campo para pesquisar minha ação docente. Mas qual metodologia de investigação me seria adequada?

\section{Diários de aula: a descoberta de um percurso de pesquisa}

Embora a experiência relatada tenha ocorrido no contexto extraclasse, dentro de um projeto de extensão de moldes cine clubistas, outra experimentação empreendida na sequência influenciou minhas percepções sobre o recorte do objeto desta pesquisa. É importante citá-la, pois ela ocorreu no âmbito do ensino em diálogo com a extensão e funcionou como uma espécie de piloto para esta investigação.

A experiência foi a condução compartilhada de uma disciplina de Núcleo Livre ${ }^{3}$ $(\mathrm{NL})$, oferecida em conjunto por duas colegas e eu com o intuito, no início um tanto vago, de ensinar por meio da sensibilização estudantil em relação a ações de extensão universitárias. Nesta disciplina, apesar da característica de trânsito livre que caracterizava a proposta do $\mathrm{NL}$, cerca de $80 \%$ dos alunos matriculados eram do curso de Comunicação Social - Publicidade e Propaganda. Assim, sensíveis às suas inquietações sobre a formação, algumas das quais nós professoras também compartilhávamos, pensamos juntas alguns encaminhamentos: acrescentamos na bibliografia $O$ mestre

\footnotetext{
2 Conferir (SATLER, MARTINS, 2012a).

${ }^{3}$ Opção que a Universidade Federal de Goiás (UFG) oferece para propostas de ensino experimentais com ementa aberta e trânsito estudantil livre, ou seja, estudantes de todos os cursos da instituição se desejarem, podem se matricular. Dependendo da procura pela disciplina, a média global do/a estudante é o critério de desempate para se conseguir a vaga. Quase todos os/as alunos/as de graduação da UFG precisam de horas de NL para integralizar sua carga horária e podem cursar aqueles que julgarem de maior pertinência e interesse.
}

Revista Digital do LAV - Santa Maria - vol. 9, n. 3, p. 35 - 59 - set./dez. 2016 ISSN 1983 - 7348 http://dx.doi.org/10.5902/1983734824180 
ignorante (RANCIÈRE, 2002), adotamos como metodologia de avaliação o uso de diários de aula e como espaço de experimentação o Pezinho de Jatobá4. A produção dos dados deste trecho da pesquisa ocorreu no contexto de aula e mesmo que todos/as tenham consentido em participar como sujeito da pesquisa, assinando também o Termo de Autorização de Uso de Imagem e Depoimentos, opto por nomes fictícios para os/as estudantes envolvidos/as.

Da leitura de Rancière (2002) particularmente tinha uma expectativa/questão bem intuitiva e vaga na época, que hoje traduzo assim: ao propor que os/as estudantes se coloquem a conversar em coletividade sobre construir e interpretar imagens, eles/elas tal como "mestres ignorantes" poderiam repensar o modo como encaram e lidam com a formação acadêmica que vivenciam? Era um risco. Não sabia se isso poderia acontecer de fato, em qual dimensão e em que nível reflexivo. Mas busquei experimentar. E apesar da disciplina ter também os interesses das minhas colegas ${ }^{5}$, esse era o meu principal.

Meu objetivo era duplo, portanto. Ao mesmo tempo em que gostaria de chamá-los para o exercício da extensão universitária, buscava em tal prática a fecundidade da reflexão sobre sua própria formação e, mais do que isso, sobre a descoberta de um modo próprio de aprender. De certo modo, interessava-me em provocá-los à independência formativa, que Rancière (2002) chamou de emancipação intelectual.

Os encontros ocorriam nas quintas-feiras, nas dependências da universidade, e nos sábados na sala do Pezinho de Jatobá, no bairro Shangry-lá, onde, por meio de exibições aos moldes cine clubistas, assistimos, debatemos, mas também construímos imagens com as crianças do projeto. As atividades e filmes exibidos para as crianças do Pezinho eram pensados coletivamente pelos/as estudantes e por nós apoiando e provocando. Mas eram eles/elas que as avaliavam, bem como pensavam sobre o que aprendiam escrevendo semanalmente um diário de aula, como pode ser visto nas figuras 1 e 2 .

\footnotetext{
${ }^{4}$ Criado pela professora Lisbeth de Oliveira, o Pezinho de Jatobá é um projeto de extensão vinculado à Faculdade de Informação e Comunicação (FIC/UFG), no qual algumas ações de educação ambiental, fotografia e vídeo acontecem há quinze anos no bairro Shangry-lá, vizinho do Campus Samambaia da UFG, periferia de Goiânia - Goiás.

${ }^{5}$ Batizada de Sincronicidade e Comunicação: Criação Coletiva, a disciplina foi ministrada pelas professoras Ana Rita Vidica Fernandes (na época, coordenadora do Pezinho de Jatobá e professora de Fotografia no curso de Comunicação Social - Publicidade e Propaganda) e Maria Júlia Pascali (professora no curso de Direção de Arte) e por mim, no segundo semestre de 2011.
} 


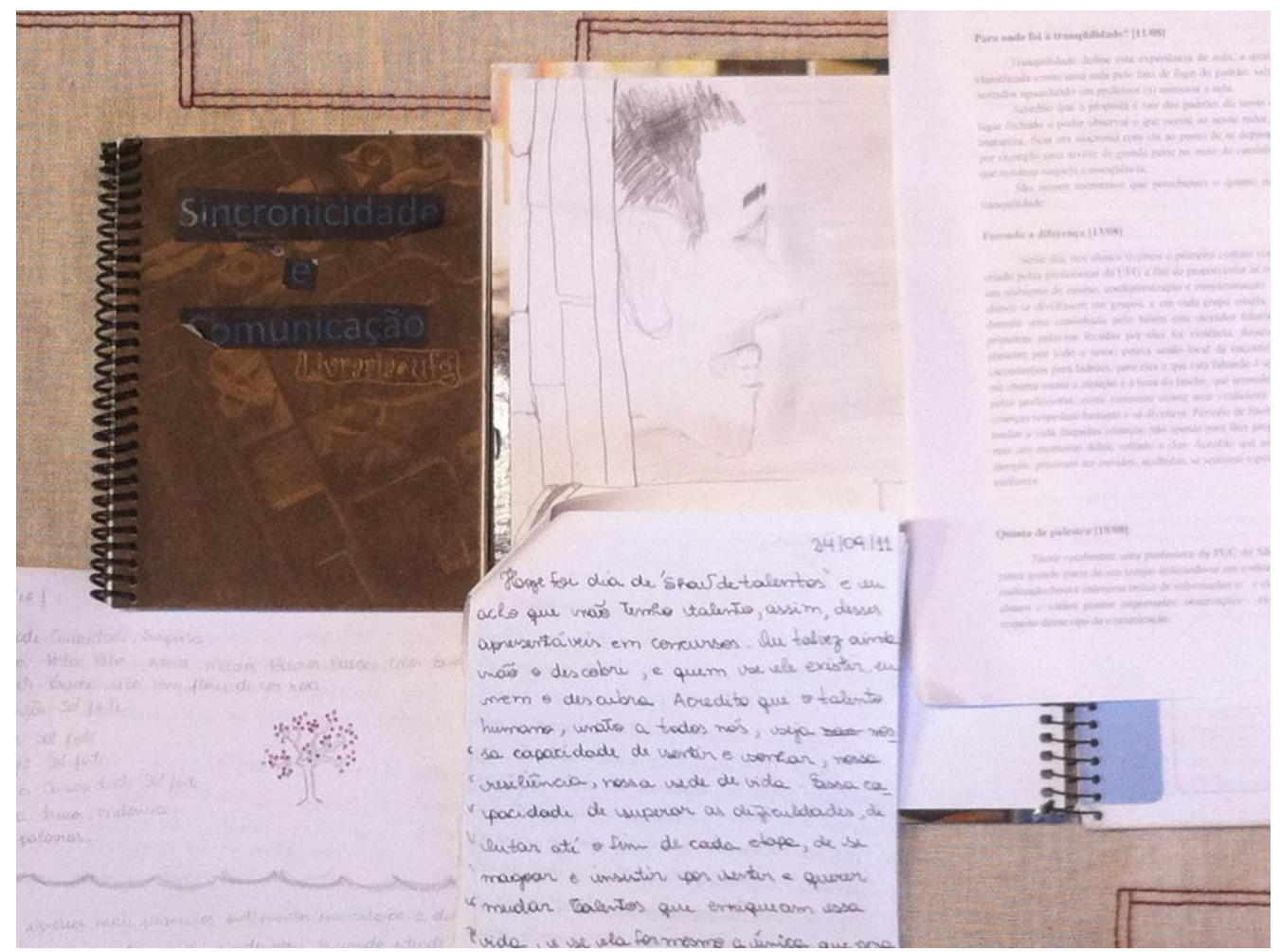

Figura 01: Diários de estudantes em formato livre (foto da autora)

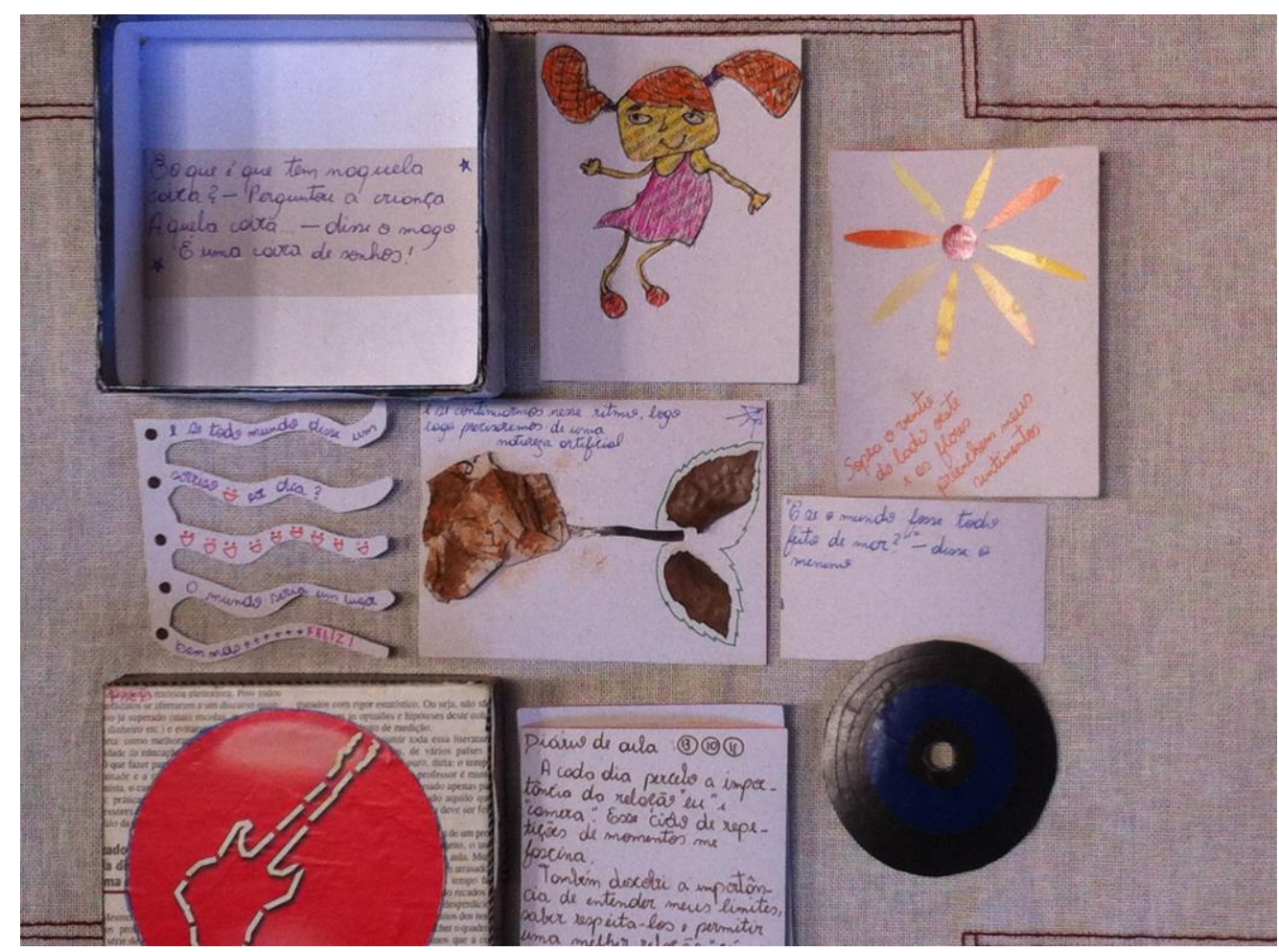

Figura 01: Diário de Maria José (foto da autora) 
A partir de alguns relatos dos diários de aula dos/as estudantes e meu, pergunto que tipo de conhecimento, percepções e sensibilidades foram apreendidas do proposto? $\mathrm{E}$ ainda o que se descobriu e se compreendeu sobre uma aprendizagem atravessada por uma ação de extensão? Para melhor apreensão, dividi os relatos nos seguintes blocos temáticos, sobre os quais busquei refletir na sequência:

1) A disciplina em relação às autodescobertas estudantis.

Após o primeiro contato com as pessoas da comunidade Shangry-lá e as brincadeiras produzidas por todos, percebi que um dos principais objetivos da disciplina é a simples comunicação para entender a relação com o próximo de maneira não 'mecânica', mas sim 'orgânica'. Usando termos sociológicos, digo que a relação com desconhecidos normalmente se dá por interesses, o que tornou a experiência no Shangry-lá um tanto diferente e curiosa. (Diário de Renata Silva, sem data especificada)

Hoje depois do Pezinho eu peguei para ler meu diário e eu percebi o quanto que está mudando minha relação com as crianças, a maneira como eu estou escrevendo, como eu também estou mudando... antes eu era mais teórica, eu estava mais presa na disciplina; agora eu estou bem mais envolvida no projeto, estou mais ligada, até sentimentalmente... mas eu realmente não acho que essa mudança seja ruim, eu acho realmente que era o que a disciplina estava propondo desde o início - sensibilizar os sentidos. E eu acho que está dando certo. (Diário de Ana Luiza Carla, em 5 de novembro de 2011)

Não costumo relatar as quintas-feiras, mas preciso ao menos deixar registrado o quanto elas foram e estão sendo enriquecedoras, tem sido uma espécie de autodescobrimento, o qual ainda não me sinto à vontade para compartilhar [em público]. [...] Conclui que no decorrer dos anos tive mais professores do que mestres, aprendi que o melhor planejamento a gente faz fazendo, que o silêncio não precisa ser tido como constrangimento, que gritar faz emergir forças, que 'invadir' é preciso, lembrei que tenho outros sentidos além da visão, chorei novamente vendo os outros chorarem, me arrepiei com a história de superação de um filme [pelo contexto não foi possível reconhecer sobre qual filme ela se referia], lembrei e senti que mesmo com um mundo de obrigações e 
responsabilidades ainda estou viva e é claro preciso viver. (Diário de Carolina Lima, em 28 de outubro de 2011)

Desde o início, nós professoras tínhamos os seguintes objetivos para a disciplina, - Sensibilizar os sentidos e a percepção dos elementos da natureza a partir de vivências vinculadas ao Projeto Pezinho de Jatobá;

- Construir coletivamente ações no bairro Shangry-lá a partir do levantamento de potencialidades e desejo de atividades e saberes dos alunos e dos moradores do bairro;

- Propiciar a construção de um novo olhar por parte das professoras, dos alunos e das crianças sobre o bairro;

- Desenvolver maneiras criativas e lúdicas de divulgação e ações sociais e culturais no Projeto. (Sincronicidade e Comunicação: Criação Coletiva, 2011)

Observando estes objetivos em relação aos relatos dos/as estudantes acima, noto que dada a característica experimental da disciplina, uma vez que oferecida no contexto de um curso que, pelo menos em linguagem corrente, busca formar profissionais para atuar em agência de publicidade, é realmente muito difícil compreender porque abordar os sentidos, a sensibilidade, a criação coletiva, as potencialidades e os desejos de cada participante envolvido.

Certamente porque a racionalidade técnica tenha expulsado do campo do conhecimento, tido como de real valor, tais objetivos são supostamente de menor importância. Noto como a primeira estudante, percebendo isso, busca articular "em termos sociológicos" os objetivos de estarmos naquele aprendizado, sugerindo que na sociologia, sendo uma ciência que trata de questões sociais, ela teria explicações para tamanho estranhamento.

Os dois relatos seguintes, já escritos próximos ao fim da disciplina e na sua metade, respectivamente, demonstram outra apreensão de tais objetivos, bem como uma apropriação de práticas que foram vivenciadas em coletivo nos seus discursos. Se por um lado, a proposta era considerar os sentidos na construção do conhecimento, noto nestas duas últimas narrativas a compreensão de que para se fazê-lo é preciso abrir mão da teoria. Como isso não estava proposto uma vez que tínhamos leituras e discussões regulares, me pergunto por que foi percebido desse modo tão dicotômico, tão dualista?

Relendo os objetivos da disciplina, penso que poderíamos ter problematizado também a necessária relação entre a objetividade e a subjetividade na construção do 
conhecimento, evitando pender excessivamente para um lado ou para o outro. Mas observo ainda que tais relatos expressam uma negação da racionalidade técnica muito mais por desconhecê-la do que por buscar superá-la.

2) Aprendizagens e leituras feitas sobre o mundo em que se inserem.

Ontem, segunda-feira (19/09), fui a uma livraria na Rua 4, no Centro, em busca de livros relacionados ao curso de Publicidade. Ao dizer ao livreiro da minha preferência, ele confuso com a diferença entre marketing e propaganda me questionou sobre. Tentei ao máximo respondê-lo. E acho que tive êxito. Depois que saí da livraria, andando ali pela Avenida Goiás, refleti sobre o ocorrido: eu, uma garota de 19 anos que, aparentemente, não sabe quase nada sobre a vida estava ali explicando a um homem de quarenta e tantos anos sobre uma coisa que eu tinha conhecimentos. Isso parece uma coisa boba, mas eu acho que tem relevância e ligação com a disciplina de Sincronicidade. Experimentei na prática o que havia sido dito na última aula. (Diário de Antônia Gonçalves, sem data especificada)

Eu tinha pegado um livro lá na estante que tinham me pedido e de repente uma das crianças começou a contar a história só olhando as figuras e aí depois que ela tinha acabado, eu falei "Ixe, eu acho que eu estou diante de um grande contador de histórias, me dá um autógrafo, vai que depois você vira escritor aí, heim?" "- Não, tia, eu quero é ser médico!" Eu sei lá, eu comecei a pensar o quanto seria difícil aquela criança alcançar seu sonho. Eu pensei o quanto seria bom se aquelas crianças realmente tivessem oportunidades para alcançar o que quisessem. Não adianta pensar que todas as crianças têm chances iguais porque é óbvio que não é assim. (Diário de Ana Luiza Carla, em 12 de novembro de 2011)

Os relatos acima traduzem modos distintos de apropriação do conhecimento construído durante as aulas da disciplina para percepção sobre a realidade em que se insere. Na primeira narração, a estudante se percebe capaz mesmo não sabendo "quase nada sobre a vida" de discorrer sobre assuntos referentes ao seu curso para alguém mais velho. Seu espanto traduz a introjeção de uma ideologia em que aluno/a é desprovido da luz do conhecimento, próprio da etimologia da palavra. Além disso, demonstra também a 
ideologia de que todas as pessoas mais velhas, só pelo fato de serem mais velhas, sabem mais.

O que torna este relato interessante é o fato de a estudante ter percebido o momento vivido, ter refletido sobre ele e considerá-lo assunto para compor seu diário de aula, visto que foi uma escolha dela estabelecer e argumentar sobre a relação entre sua experiência vivida lá na livraria e o que se estudou em aula lá na universidade. Portanto, sua capacidade de levar a reflexão construída num contexto de formação para o mundo da vida, para seu cotidiano é que faz tal narrativa rica.

O segundo relato, como o primeiro, é também marcado pela reflexão. Contudo, aqui a reflexão está impregnada pela frustração e impotência diante de um envolvimento sentimental com as crianças do projeto, uma vez que está logo na sequência do relato feito no dia 05 de novembro (vide bloco de relatos 1 ), da mesma estudante.

O afeto, neste caso, constitui solo fecundo para a reflexão sobre sua frustração e impotência diante do desejo de uma criança, que mora no bairro ao lado da universidade e na periferia de Goiânia, querer ser médico quando crescer. O que a estudante percebe é a concretude das injustas oportunidades de acesso à educação que o sistema de classes da sociedade brasileira tem produzido, mas o faz de uma perspectiva próxima e mediada pelo afeto. Em que tal percepção acarreta em termos práticos e objetivos para a estudante e para a criança? Para esta questão não tenho resposta. Mas longe de ser uma dúvida paralisante, ela me move a continuar buscando respostas.

3) Apreensão da proposta, a criação coletiva, o diário de aula, as mostras fílmicas e as produções audiovisuais.

Esse 'método' baseado no coletivo, onde todos são parte de um só, onde todos temos a liberdade de trocar de 'função', a todo o tempo estamos ensinando e aprendendo sem distinção de funções. Nesse formato também podemos e devemos exercitar nossos ouvidos, devemos ouvir o grupo, prestar atenção no outro e sentir. [...] Eu já obtive minha nota na disciplina. Não a que eu dei, conforme esforços ou aplicação, mas sim a que eu recebi da disciplina e acho que foi tão válido e essencial que não pode ser mensurado nem correspondido com avaliações formais. Fica a questão "Que nota você atribui a uma experiência de vida?" "Como mensurar os benefícios?" [...] Tudo o que vivemos ou vimos serviu de aprendizado, os filmes foram muito motivadores dessa mudança que aconteceu em mim. Eu acredito que os sonhos são muito incentivados pelas histórias infantis e ao contá-las, estimulou a [minha] imaginação, pois [os sonhos] 
são potenciais transformadores da realidade. [...] Acho que para nós alunos foi mais proveitoso porque aprendemos muito com isso. Para as crianças devíamos ter estimulado mais a temática dos filmes, que eram bons. (Diário de Isis Alexa, sem data especificada)

Dia de "Os Smurfs". Não achei certo exibir esse filme. Ele não estava fora do cinema ainda. Tudo isso em prol do "decidir coletivo". Até que ponto pode-se abrir mão de alguma coisa para beneficiar outra? Não estamos aqui para perceber e melhorar mais? Então por que fazer assim? Fiquei chateada. Até loquei outro filme (para se caso não desse certo o primeiro, ele o substituísse). Confesso que queria mesmo era que passasse o meu filme, mas porque o meu filme? Olha só eu também sendo egoísta, né? Realmente confuso. (Diário de Manuela Faria, em 10 de setembro de 2011)

Gostei bastante da programação deste dia, Castelo Rá-Tim-Bum faz parte da minha formação, da minha infância, não perdia um episódio da série e adorei assistir o filme que fizeram sobre ela. As mensagens educativas, as músicas, a história de amizade sempre me fizeram gostar ainda mais dessa encantadora história. Ao assistir novamente, consegui associar um aspecto da história com a questão do diário do Núcleo Livre. Quando Nino, o personagem principal, se depara com seu livro de magia em branco vê o quanto foi desleixado, e tentando se explicar diz que não sabe magias ao certo para escrevê-las. Porém seus tios Ihes explicam que esse aprendizado é adquirido com o tempo, que ele (o Nino) deveria sempre escrever algo em seu livro, mesmo que não achasse ser algo mágico. Percebo a associação no momento em que o diário nos foi proposto para que a cada encontro escrevêssemos nossas observações, nossos sentimentos, a fim de nos auto-avaliar, nos conhecer mais e perceber aspectos ao nosso redor. (Diário de Joaquim, em 12 de novembro de 2011)

Querido diário desatualizado. Quero aproveitar essa página para colocar minhas percepções do projeto, da oficina, da disciplina e dos filmes. Os filmes: as mostras [eram duas: uma na UFG só para os estudantes e outra no Pezinho de Jatobá voltada para as crianças] me trouxeram um novo olhar ao mundo. Perder o olhar de 'não posso, não consigo'. Tudo começou pelo cartaz, pelas correções. A escolha dos filmes e seu conjunto trouxeram complementos uns aos outros, filme a mim. O filme Jacquot de Nantes me trouxe novos ânimos para tentar e experimentar. [...] O diário de aula faz reviver a 
vivência, relembrar, faz crescer e perceber suas percepções. (Diário de Rogério Lemos, sem data especificada)

Esse dia eu acho que descobri o que é Sincronicidade, Comunicação, Criação e Coletiva, e tudo junto também. A ideia principal ou inicial do monitor foi fraca, pois não era bem stop motion. Mas logo depois de fazer o que ele propôs, o que ninguém interrompeu e sim colaborou, surgiu a ideia que daria um verdadeiro stop motion de objetos reutilizáveis. Surge a corrida de tampinhas, de tamanco, a centopéia e o pássaro. A corrida começou e a sincronicidade ainda não estava rolando, mas começou a surgir, aparecer até que pronto: todos ajudam, uns operam a câmera, todos dão ideias, os que conseguem fazem, os que não fazem também. A melhor parte que achei foi na da latinha e a do pássaro. Na primeira, eu, o João (fotógrafo) e os participantes estávamos tão ligados que fizemos esse stop motion rapidão. Eu amassava [a latinha] e já tirava a mão, o João fotografava e todos palpitavam e orientavam. Tudo isso acontecia sem ordens diretas, estávamos em sincronicidade, um com o outro, sabendo o que outro precisava e qual parte era a minha, a do outro, quais eram nossas vontades e escutas e as dos outros. (Diário de Rogério Lemos, em 5 de novembro de 2011)

Visita ao estúdio de rádio. Conheci o estúdio, os equipamentos e o profissionalismo do Tom [técnico de áudio da Faculdade de Informação e Comunicação (FIC)]. Acho que foi a melhor experiência minha durante a oficina. [...] Os meninos acharam o máximo. Daremos voz ao stop motion, histórias, contos e vida. Ganhamos tudo de volta, principalmente alegria, esta que sempre irá me acompanhar e nunca deixará dizer mais que o outro ou eu não sou capaz. Que se ele não consegue, posso dar a primeira ajuda ou abrir os caminhos para que ele consiga sozinho. Ou mesmo comigo. Abrir os olhos para tudo, ver que todas as experiências são válidas, que o outro não precisa ser doutor, Phd ou etc., para me ensinar e que o conhecimento eu posso descobrir. (Diário de Rogério Lemos, em 23 de novembro de 2011)

Muitos assuntos são suscitados nos trechos acima. Em primeiro lugar, é importante lembrar porque nós, professoras, optamos pelo diário de aula como instrumento de avaliação. Nossa proposta se fundamentou inicialmente na educação da cultura visual, que se dedica problematizar a formação de professores, pesquisadores e 
produtores de conhecimento focado no fazer docente no campo da cultura visual, que por sua vez, Martins e Tourinho (2011, p. 7) esclarecem que

Fermentado pela história da arte, sociologia, filosofia, antropologia, arte-educação, estudos culturais, estudos feministas, pós-estruturalistas e pós-colonialistas, o campo da cultura visual busca e realiza mudanças nas maneiras como compreendemos os fenômenos visuais, especialmente nos fazendo pensar sobre os usos que damos às imagens e artefatos. Faz-nos pensar também sobre os impactos que as imagens e artefatos promovem nos modos como concebemos, agimos e sentimos no mundo.

Além disso, nossa proposta também se fundamentou na escrita de diários a partir de Oliveira (2011), mas considerando uma série de adaptações que fizemos, pois os discentes da turma não estavam se preparando para ser professores das crianças do Pezinho. O que ocorreu, a Isis relata com clareza, foi o esforço de experimentar um "método baseado no coletivo" de acordo com o qual "a todo o tempo estamos ensinando e aprendendo sem distinção de funções".

Método este que Manuela, no relato seguinte, reclama ser confuso pelo conflito ético que vivenciou neste coletivo. Curiosamente este conflito só apareceu no diário escrito, não veio a público na sua leitura coletiva apesar de que pela sua ação de locar e levar outro filme por conta própria para as crianças assistirem traduza um incômodo veemente. Segundo Oliveira (2011), a escrita semanal do diário e sua posterior leitura no coletivo potencializa a troca de informações em grupo, a discussão de problemas enfrentados e o acolhimento de dúvidas trazidas pelos relatos. A organização do pensamento para a escrita e posterior reorganização para a leitura potencializa a reflexão sobre seus modos de aprender, tornando-a inteligível ao outro. 


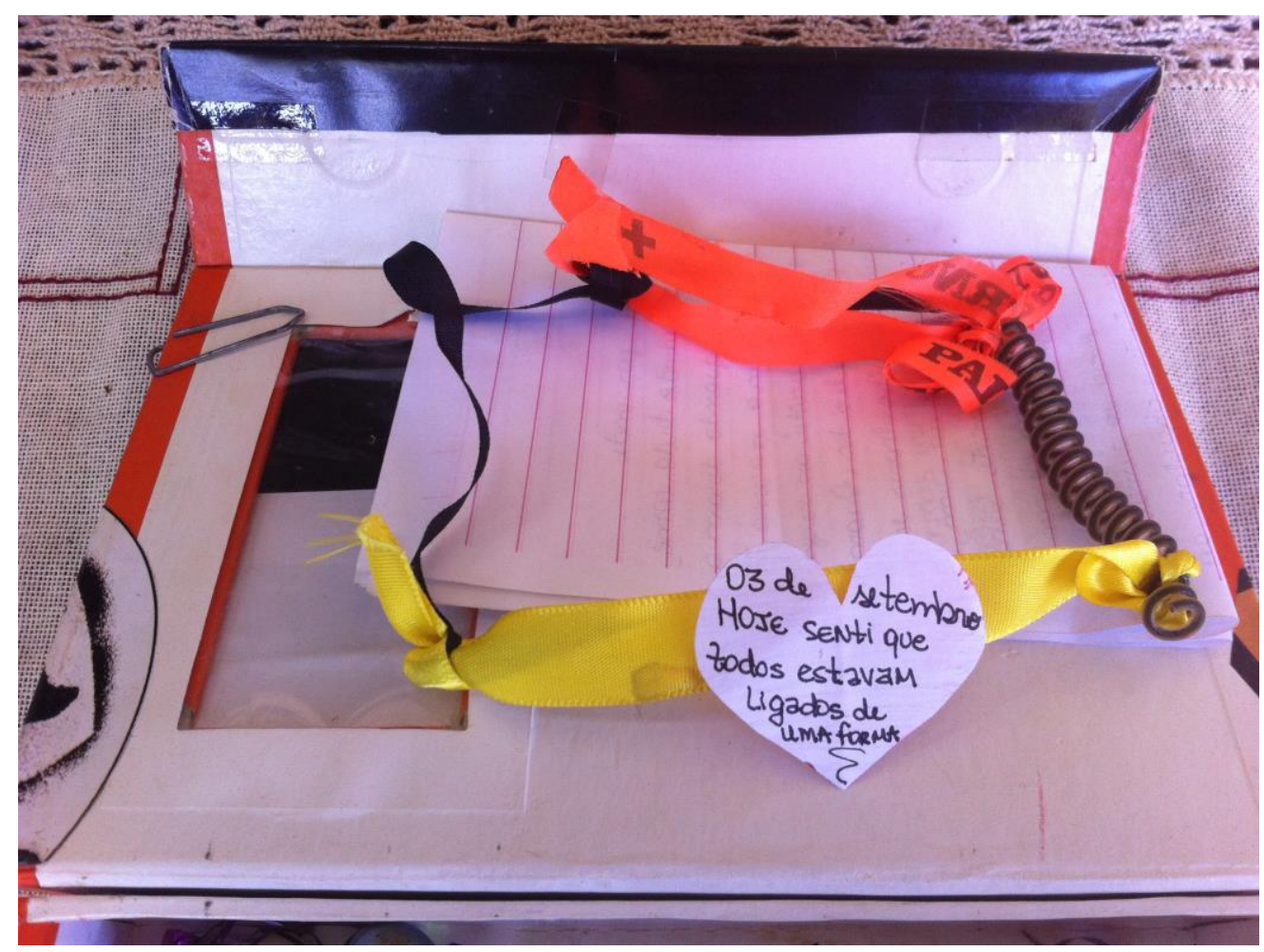

Figura 01: Diário de Flávia Vita (foto da autora)

Como a figura 3 nos apresenta, o círculo de fitas distintas amarradas umas as outras, objeto concebido pela estudante Flávia, representa visualmente esse "método baseado no coletivo" nas suas imperfeições, seu inacabado, sua irregularidade e por que não sua confusão, como apontou acima Manuela? Tal como as fitas diferentes compõem um mesmo círculo, o coletivo foi composto de singularidades, que reunidas em torno de alguns objetivos comuns, como os da disciplina em questão, se prestam a reunir esforços para alcançá-los. Tal reunião não foi destituída de conflitos, tanto quanto a aprendizagem que dela emerge. Mesmo não vindo a público na época, tal conflito foi registrado e aparece posteriormente, nesta análise.

Observo a partir deste bloco temático de relatos que a proposta do "método baseado no coletivo" operou com muitas questões e muitas delas complexas. Isis, por exemplo, questiona em seu relato: como atribuir nota a sua experiência de vida? Seu argumento reza sobre uma inadequação de avaliações formais para tais aprendizados e se fundamenta em uma autoavaliação segundo a qual ela já teria mensurado os benefícios que eles trouxeram a ela. Assim, ela cita os filmes como motivadores de mudanças, o que implica em compreendê-los como fontes de um aprendizado que se apresenta como conhecimento e autoconhecimento simultaneamente. 
Ao mesmo tempo, ela como parte proponente dos filmes e atividades sobre eles avalia que faltou discutir mais sobre seus temas com as crianças do Pezinho, o que implica uma divergência da decisão coletiva ou do desconhecimento desta. Desde a primeira exibição, as crianças mostraram dificuldades de interpretar os filmes verbalmente, por isso, o grupo avaliou, refletiu e optou por atividades cujas linguagens pudessem fazer emergir a compreensão dos seus temas.

É sintomático observar que o mesmo diário que tece críticas às avaliações formais em função de uma imensurável experiência vivida, avalie que os temas deveriam ter sido menos experimentados pelas crianças. Tal observação aliada a uma frequência irregular aos encontros e ainda à afirmação "eu já obtive minha nota na disciplina. Não a que eu dei, conforme esforços ou aplicação" sugere que sua avaliação sobre os temas dos filmes com as crianças representa muito mais desconhecimento da decisão coletiva do que divergência.

Sugere ainda que mesmo tendo havido uma experiência de vida imensurável, o que é inegável lendo todo seu diário, sua nota na disciplina está mais marcada por um discurso que justifica poucos esforços ou aplicação em relação à disciplina, ao grupo e a construção coletiva dos processos do que pela crença de não ser possível avaliar formalmente as experiências.

Outro aspecto da questão. Embora Peruzzo (2003) teça críticas ao uso de filmes longos no ensino de Comunicação, compreendendo sua escolha como símbolo de enrolação, observo o quanto sua argumentação precisa ser relativizada a partir do contexto aqui analisado. Dificilmente trechos de filmes provocariam as mesmas reflexões que motivaram as mudanças pessoais citadas por Isis. Tais mudanças dizem respeito à ampliação de seus pontos de vista, de suas experiências de vida e da sua sensibilização às questões anteriormente não pensadas, como a potência dos sonhos para a construção de outras realidades.

No entanto, é preciso observar que toda essa potência se concretizou não apenas pelo ato de ver filmes nas aulas, mas por todo um "método baseado no coletivo", que resumidamente se traduz por um conjunto de filmes escolhidos a dedo para serem vistos, sentidos e interpretados em um coletivo de professoras e universitários/as, conjugado com leituras, exercícios e elaborações de ações para que outro conjunto de filmes seja visto, sentido e interpretado por outro coletivo: de professoras, universitários/as e participantes do Pezinho de Jatobá.

Assim, os filmes compõem a proposta como fontes de conhecimento, tanto quanto um texto e seu estudo. Por isso, o ver o filme, senti-lo, interpretá-lo em coletivo possibilitou, tal como a leitura do diário de aula, discursar sobre a própria experiência do 
visto, associando temas a outros conteúdos de leitura ou do vivido no cotidiano, refletindo sobre como tais temas foram apresentados pelos/as cineastas e como produziram sentido em e para cada um/a.

Ainda cito também o relato de Rogério e como os filmes inspiraram-lhe uma nova atitude pessoal, pois "as mostras me trouxeram um novo olhar ao mundo. Perder o olhar de 'não posso, não consigo'". Para ele, as mostras, tanto o conjunto de filmes apresentado na universidade, como aquele exibido no projeto, são associadas a uma atitude de experimentação principalmente porque como monitor do Pezinho, ele se viu na responsabilidade de divulgar os filmes junto ao público do bairro, elaborando cartazes pela primeira vez e montando oficinas de apoio aos dias de exibição. Certamente, por isso, ele teve uma relação privilegiada com a produção de imagens em movimento em detrimento dos/as demais estudantes. Ele então foi o único que acompanhou, por exemplo, a produção de stop motion do princípio ao fim, ajudou a conceber, acompanhou no estúdio a gravação do áudio para ela e a sua edição em vídeo.

Observo que a complexidade da proposta da disciplina em suas diversas variáveis (aulas na universidade e na sala do projeto; aulas sobre textos e sobre filmes; aulas para elaboração de atividades no projeto e aulas para leitura coletiva dos diários; aulas para discutir verbalmente os filmes e aulas para experimentar produzi-los) mostrou-se difícil de ser administrada, de modo que em termos de apropriação das produções, o Rogério, por ser monitor, foi um dos poucos que relatou sobre elas. Isso implica que os/as outros/as estudantes pouco construíram conhecimento sobre experimentar em produzir.

Se o relato do Rogério traz uma vinculação direta entre a experiência do visto com a necessidade de experimentar a produção de modo que os filmes lhe inspiraram sair de uma zona de conforto no âmbito da aprendizagem, aquela que recebe passivamente os conhecimentos, para desbravá-los, observo que o "método" peca ao não possibilitar essas mesmas experiências a todos/as participantes. Neste sentido, ele nega explicitamente que os titulados doutores ou $\mathrm{PhDs}$ poderiam the ensinar algo, o que implica em uma compreensão tão ideológica quanto a noção de aprender por meio de transmissão passiva. Nem um extremo, nem outro: nem recepção passiva, nem independência total. Noto nas afirmação de Rogério uma leitura problemática da proposta de Rancière (2002). Com sua leitura, me pergunto se não seria a proposta ela mesmo problemática. Sobre essa discussão, ver os próximos capítulos.

$\mathrm{O}$ relato do Joaquim traz outro aspecto dessa construção de conhecimento. Em um dos filmes exibidos especialmente para as crianças do projeto, é o universitário que se apropria de um trecho da sua temática associando-o à feitura do seu próprio diário de aula, um método de avaliação exclusivo dos/as estudantes. De um filme destinado 
aos/as participantes do Pezinho, Joaquim se vê como o personagem Nino, que se julga desleixado por não ter escrito nada no seu livro de mágica.

Joaquim associa seu diário de aula ao livro de Nino, apreendendo do filme o conselho que os tios do personagem lhe dão sobre a necessidade de se escrever nele, mesmo que não tenha um assunto sobre magia. O que Joaquim faz neste trecho é perceber que o diário de aula precisa ser escrito mesmo que o que ele tenha para dizer não Ihe pareça ainda algo espetacular ou mágico. Foi o que tentou fazer a Liz, no diário da figura abaixo, utilizando o suporte que tivesse a mão, como guardanapos de papel, blocos de evento e mesmo o SMS (Serviço de Mensagens Curtas) do seu celular para guardar seus registros em qualquer momento.

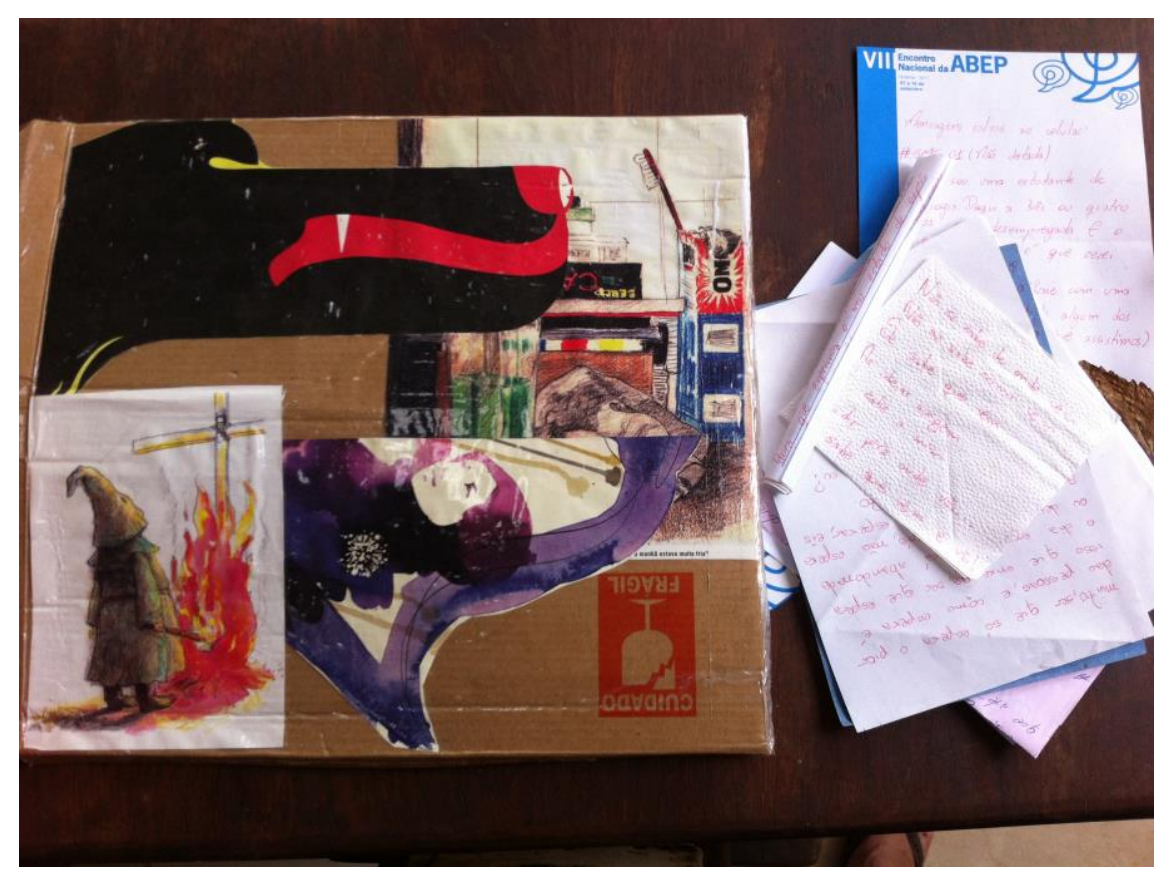

Figura 02: Diário de Liz Forte (foto da autora)

De modo menos figurado, Rogério traduz o que ele compreende sobre o diário de aula, que Ihe faz "reviver a vivência, relembrar, faz crescer e perceber suas percepções". Dada sua inovação como instrumento de avaliação em cursos de Comunicação, o diário de aula gerou estranhamento nos/as estudantes. Por isso em vários diários notei uma necessidade espontânea de seus/suas autores/as explicar para si mesmo/a o que ele é e como opera. Considerando que em nenhum momento isso Ihes foi solicitado, observo que pode ser do próprio instrumento sua potência reflexiva. 
4) Sobre uma aprendizagem atravessada por ações de extensão.

Como não se interessar pelas crianças, não é mesmo? As crianças são o que realmente dá graça ao projeto, todas elas, em especial o Pedro e Rani, sempre lá, sempre os que tomam conta de tudo, meio que os líderes entre as crianças, apesar de todos terem seu importante papel. Eles quebram um pouco, ou bastante o pragmatismo dos adultos durante as atividades, nos surpreendem com talentos novos, a falta de medo de encarar as coisas e, claro, sua doçura. Os adultos estão aprendendo muito com elas, outro dia o Rafael, que nem entregue o diário tinha, por temer escrever, leu um poema feito por ele. Há quanto tempo eu não vejo algo assim, não é? A superação! (Diário de Pedro Martins, sem data especificada)

Hoje foi o dia da realização da gincana pensada pela Sofia e pelo Iuri. Eu e a Anne fomos fazer a pipoca em uma casa [de uma moradora do bairro], próximo à sala do Pezinho. Chegando lá não fomos bem tratadas, foi realmente uma situação constrangedora. Mas logo depois fomos à casa da Valesca e o clima foi completamente diferente. Fomos muito bem recebidas. Fiquei pensando: será que estou incomodando? Me veio a lembrança do começo do Pezinho, quando eu ainda não me sentia totalmente incluída e queria participar mais, mas não sabia como fazer isso. Mas a avó da Valesca nos tratou de uma forma tão calorosa e tão acolhedora, que acho que fez a mim e a Anne esquecermos do mal estar ocorrido. Mais uma vez o Pezinho me mostra o verdadeiro sentido de deixar-se afetar e sensibilizar. (Diário de Teresa Ávila, em 19 de novembro de 2011)

Teatro no Pezinho [sobre o filme Alice no País das Maravilhas]. Apesar dos risos e da diversão, a professora insegura - a neura - insiste em bater a porta: toc, toc, toc. Será que não foi caótico demais? Contudo alguns comentários marcaram este dia. O Luis disse-me "agora estou entendendo como posso atuar com eles. Eles podiam levar estes textos [ele se refere aos trechos de um capítulo de Alice no País da Maravilhas] e pedir que suas mães leiam para eles". A Érica, moradora do bairro, disse "agora vou fazer teatro na minha casa". A Ana Rita disse-me, uns dias depois, "de repente, eles sentem que o teatro não é mais tão distante deles". Eu sinto que o caos incomoda, mas acho que pode ser esse o caminho. (Diário de Lara Lima Satler, em 3 de setembro de 2011) 
Recorro agora ao interesse principal que me motivou a encarar toda essa empreitada, que foi, em outras palavras, a primeira experimentação de uma formação autoreflexiva envolvendo estudantes, um projeto de extensão e três professoras, sendo eu uma delas. Para pensar nos relatos acima foi preciso considerar também a experiência de uma das docentes com teatro e cinema e das outras duas em fotografia e vídeo, bem como distintos interesses conceituais e visões de mundo. Tudo isso foi articulado para a construção da seguinte ementa da disciplina,

Treinamentos e jogos para o estado de criação e construção coletiva, com percepção e adoção de uma atitude que incorpora valores e critérios do Novo Paradigma como simplicidade, solidariedade, profundidade, espiritualidade, interioridade, respeito ao diferente, unidade na diversidade, cooperação, desapego e visão sistêmica, buscando desenvolver a expressão artística multidisciplinar de um ser harmonioso e integrado ao presente, onde se exercite: democracia, cidadania, autoestima, sociabilidade e novas posturas, visões e soluções diante do planeta e de todos os reinos, através de vivências em sala de aula, duas em Pirenópolis e exibições, conversas e produções de filmes, de maneira coletiva. Cruzamento metodológico e conceitual entre educomunicação, sincronicidade e criação coletiva, buscando uma prática e reflexão muito mais a partir do processo que do produto final. (Sincronicidade e Comunicação: Criação Coletiva, 2011)

A partir da releitura desta ementa, noto como ela pouco contemplou as expectativas sobre ensino que tinha na época em relação à empreitada. Considerando também se tratarem de fruto de uma construção coletiva entre as três docentes, observo que quem de nós tinha mais seguranças conceituais prevaleceu, algo muito frequente nestes processos. Além disso, como primeira experimentação, os conceitos fundamentais que tinha sobre aprender, ensinar, no âmbito da universidade e num projeto de extensão se encontravam ainda fugidios, vagos e muito intuitivos. Ressalto ainda que a ausência da perspectiva e das peculiaridades da extensão nesta discussão de modo algum indica sua menor importância, revela apenas que o interesse aqui analisado é um ensino atravessado pela extensão e não ela propriamente dita.

Assim, como professora não tinha ainda muita clareza sobre o que estava propondo, o que me interessava e, principalmente, no que se empenhavam minhas parceiras de condução da disciplina. Talvez por isso, tenhamos optado pela oferta da disciplina no formato de um Núcleo Livre, o que implica em termos mais abertura para experimentar e errar inclusive. O que tinha como certo era um incômodo sobre o modelo de ensino praticado no curso onde trabalhava. Em princípio era o que tinha. 
Aos poucos, fui com o grupo de professoras e estudantes delineando como todo o processo seria construído. Em nenhum momento tínhamos a intenção de criar um "método baseado no coletivo", mas acredito que a Isis interpretou a experiência de modo acertado. Foi da necessidade de ensinar o ensinado na universidade às crianças do Pezinho de Jatobá que o grupo de universitários/as se desdobrou em pensar sua própria aprendizagem. Contudo, ainda que de modo muito incipiente. Em parte pela novidade da proposta para todos/as, em parte pelo complexo das variáveis envolvidas nela.

Apesar disso, noto que estar baseado no coletivo, num momento de professoras e universitários/as e noutro de professoras, universitários/as e crianças trouxe novos elementos para se pensar o aprender. É o que nos apresenta Pedro, no seu relato. Dado o comportamento despretensioso das crianças, ele atribui a elas o papel de mestres, pois elas "quebram um pouco, ou bastante o pragmatismo dos adultos durante as atividades, nos surpreendem com talentos novos, a falta de medo de encarar as coisas e, claro, sua doçura".

Para ele, foram as crianças que ensinaram aos/as estudantes a encarar as atividades de criação sem tanto bloqueio, que ele traduz por pragmatismo adulto. Para Pedro, a capacidade infantil de se lançar à proposta sem saber ao certo no que vai dar, ou seja, despretensiosamente, tornou-se um exemplo para o colega Rafael superar uma autocrítica impeditiva de processos criativos.

A sua percepção sobre as crianças como deflagradoras de aprendizagens torna-se um exemplo do potencial formativo da metodologia diários de aula. Afinal, as crianças não são mais vividas nem mais especialistas em criação audiovisual, mas são crianças de um projeto de extensão, na periferia de Goiânia. Socialmente falando, são marginalizadas de uma suposta autoridade para se tratar sobre cinema, muitas das quais nunca estiveram em uma sala escura. O que está em questão então não é o ensino sobre cinema ou audiovisual, mas um modo de encarar os desafios criativos, de se expor perante o grupo, experimentando-se por meio de linguagens e técnicas diversas. Para Pedro, o que as crianças ensinaram aos adultos foi esse modo desprendido de lidar com a criação audiovisual. E isso só apareceu no seu diário de aula, não tendo sido mencionado publicamente em sala ou em qualquer outro contexto da disciplina.

O relato de Teresa, por sua vez, apresenta a reflexão sobre o aprendizado pela via do incômodo. Se com Pedro observo o aprender pelo exemplo, aqui o tenho pelo padecimento de uma experiência atravessada pelo constrangimento. Se de um lado temos certa valorização do lúdico e do aprender exclusivamente por meio do prazer da descoberta no pensamento educacional progressista, temos também uma compreensão 
muito romântica de ações de extensão em periferias. A reflexão da Teresa sobre o ocorrido sugere que ambas as visões pedem revisão.

Não é possível omitir o padecer, a negação do outro e o conflito de um aprendizado atravessado por ações de extensão. Também não advogo por uma educação baseada no constrangimento, na coerção, na unilateralidade das relações. Nem um extremo, nem outro. Observo da situação relatada por Teresa que, apesar de nós professoras termos buscado a prática dialógica em coletivo, foi inevitável o constrangimento. Portanto, ele pode ser incluído no aprendizado, precisa ser problematizado, não pode ser empurrado para debaixo do tapete, não deve ser limpo dos processos educativos.

Mas foi isso que fiz no desabafo do meu diário, isto é, ao me incomodar com o caos e a confusão próprios de atividades com crianças, sem o perceber, senti-me responsável por não propiciar um ambiente asséptico para as aprendizagens emergirem. Mas de onde vem essa ideia de que o aprender requer uma assepsia de confusão, caos, erros? E de onde vem a noção de que eu professora sou a grande responsável por garantir esse ambiente aos/as estudantes? E ainda o que tal perspectiva traz no seu bojo sobre a relação professora-estudante?

\section{Considerações finais}

A experiência com os diários de aula me permitiu descobrir crenças e valores sobre meu fazer docente inquietantes. Por isso, me impulsionou a buscar saberes e fazeres que envolvem o ensino em que atuo, bem como reflexões sobre a minha ação docente. E foi a partir daí que pesquisas em formação docente, especificamente nas que concebem o/a professor/a como pesquisador/a que encontrei aporte para refletir sobre tão complexas questões.

Assim, ao buscar referenciais metodológicos para uma pesquisa situada no campo da educação da cultura visual, aproprio-me de algumas discussões envolvendo a formação docente baseada na epistemologia da prática, a qual ao invés de conceber o/a professor/a como mero executor de currículos compreende-o/a como profissional reflexivo, como professor/a-pesquisador/a.

Schnetzler (1998, p. 8, grifos da autora) apresenta a necessidade de pesquisas serem realizadas por professores/as, pois nelas o investigar torna-se parte constitutiva da sua atividade docente, do seu desenvolvimento e da melhoria da sua ação pedagógica uma vez que 
Estabelecer "conversações reflexivas" sobre a nossa prática, refletir na ação e sobre a nossa própria ação, preferencialmente, num coletivo de professores, certamente promoverá a produção de conhecimentos mais úteis e substanciais para a tão pretendida melhoria educativa.

Assim, o enfoque metodológico da pesquisa-ação na minha prática docente emerge com uma série de necessárias adaptações para esta investigação. A primeira delas advém do cenário em que me atuo, o ensino superior em Comunicação Social Publicidade e Propaganda. Nele não trato da perspectiva da formação de professores/as em um coletivo de professores/as, mas com um coletivo de estudantes.

Neste contexto, a formação de professores/as faz sentido para mim, não diretamente para meus/minhas estudantes. É claro que eles/as serão beneficiados/as a partir do momento em que empreendo esta discussão, mas seus interesses profissionais imediatos são outros, ou seja, eles/as não serão necessariamente professores/as mesmo que alguns possam optar por seguir essa carreira. Esse cenário me exige adaptar leituras, como exemplificado anteriormente quando usamos os diários de aula, metodologias e práticas, bem como a reflexão sobre todas elas. Nele ainda o direcionamento das discussões é pautado constantemente pela questão "como meu aprendizado pode ser melhor?".

Se de um lado esta questão pode esbarrar de modo constrangedor em mim quando minha ação docente é um entrave para o aprendizado discente, de outro ela gera um exercício de autoformação, perspectiva que encaro como uma das hipóteses para melhorar o ensino em que atuo. Não se trata de transferir a responsabilidade de melhoria do ensino para o indivíduo, o/a estudante, que pouco pode sozinho. Trata-se de estimular uma atitude autoformativa que impulsione mudanças coletivas no modo como este/a estudante encara a sua participação no ensino, percebe o currículo e age em diálogo com outros docentes, nas instancias cabíveis, para compartilhar a construção de saberes mais significativos para o todo.

Em outras palavras, tanto eu quanto os/as estudantes realizamos exercícios de autoformação em coletivo, embora cada um busque no grupo respostas para interesses distintos. Eu, ao me propor a questão "como meu aprendizado pode ser melhor?", considero-o em relação à minha ação docente. Eu, que tenho aprendido a ser professora, sendo, busco nestes exercícios como meu aprendizado sobre o ensino pode ser melhor. Então, das conversações construídas em um ambiente dialógico com estudantes, extraio novos aspectos para aplicá-los ao ensino desse mesmo grupo e, na sequência, submeto novamente à questão por meio de avaliações coletivas e assim ciclicamente. Em todo 
esse processo conto com o acompanhamento de uma pesquisadora externa, minha orientadora de doutorado, que me indica caminhos teóricos, metodológicos e me aponta questões-chave para levar a campo e refletir sobre elas. Além disso, retomando a discussão sobre o meu percurso, todos estes exercícios são pensados a partir da experimentação de um "método baseado no coletivo", como batizado pela estudante Isis.

Assim, a discussão feita por Delgado (2007) sobre coletivo torna-se necessária, pois para ele diferentemente da ideia de comum, que faz a comunidade que nela se fundamenta se configure como unidade social, ao contrário disso, o coletivo se associa à ideia de reunião de indivíduos, por meio da qual eles percebem a conveniência de construir suas mediações juntos. A partir dessa distinção, o coletivo, nesta pesquisa, existe como ideia de reunião, a qual rege as relações, mas também potencializa a manifestação das singularidades dos agrupados.

Daí porque aliamos ao enfoque da pesquisa-ação o da pesquisa narrativa. Em diálogo com Oliveira (2011, 2013), por meio da autobiografia como abordagem desta investigação narro sobre minhas experiências historicamente constituídas a partir do lugar em que ocupo. Isto é, a experiência como professora de disciplinas envolvendo imagem e audiovisual esclarece sobre o contexto social em que estou inserida, um curso de Comunicação Social - Publicidade e Propaganda. Segundo Oliveira (2011, p. 178), a narrativa autobiográfica enquanto tratamento metodológico de pesquisa e de interpretação "é a capacidade de organizar a experiência como pautas de discussão ou como focos de investigação, como forma de construir sentido por meio da descrição e da análise dos dados biográficos".

Os dados biográficos aqui emergem da escrita de diários de aulas meus e dos/as estudantes que aceitaram participar comigo desta investigação. Mas não apenas desta fonte. As imagens produzidas e as discussões em sala ao longo da oferta de dois Núcleos Livres $(\mathrm{NL})^{6}$ são também fontes consultadas, descritas e analisadas.

Da reunião entre professora-pesquisadora (eu) e pesquisadora externa (minha orientadora) emerge a necessidade de buscar possíveis contribuições para minha ação docente advindas de coletivos focados simultaneamente na realização e no estudo do audiovisual. Assim, por meio de observação participante, entrevistas, análise de produções audiovisuais e documentos eletrônicos penso sobre modos de aprender e realizar nos coletivos Garapa e Sistema Cooperação - Amigos do Cinema.

\footnotetext{
${ }^{6}$ O primeiro ofertado em 2012/1 foi "Saberes audiovisuais colaborativos" e o segundo em 2012/2 foi batizado pelo grupo anterior de "Aprendizagens Audiovisuais Cotidianas".
} 
Uma vez que os contextos e as situações exigiram o emprego de distintas estratégias metodológicas ao longo desta investigação, a produção dos seus dados e a sua interpretação têm como referência a bricolagem, pois comprometida com o ecletismo desta pesquisa, permiti que as circunstâncias dessem forma aos métodos empregados nela (KINCHELOE; BERRY, 2007).

Daí advêm as adaptações metodológicas mencionadas, a observação do lugar social e da minha história pessoal como pesquisadora e professora em formação. Mas também a recusa a métodos tradicionais apenas para que esta pesquisa seja validada, isto é, corro o risco de ver a construção desse conhecimento tida por menos em virtude das escolhas que fui fazendo ao longo do processo.

Todavia, como um bricoleur lanço mão de diversas ferramentas para a produção qualitativa de conhecimento nesta pesquisa, compreendendo que seu método é também "uma tecnologia de justificação, ou seja, uma forma de defender o que afirmamos saber e o processo por meio do qual o sabemos" (IDEM, Ibidem, p. 17). Desse modo, avanço na reflexão pensando sobre o lugar de onde falo que nomeio cenário, só que sobre esse será assunto para um outro texto.

\section{Referências}

DELGADO, M. Lo común y lo colectivo. Barcelona, Universitat de Barcelona, 2007. Disponível em: $<$ http://www.google.com.br/url?sa =t\&rct=j\&q=\&esrc=s\&source=web\&cd =1\&ved =0ahUKE wioi96QoazKAhUJEZAKHdkZABMQFggcMAA\&url=http\%3A\%2F\%2Fmedialabprado.es\%2Fmmedia\%2F0\%2F688\%2F688.pdf\&usg=AFQjCNF3UuOz2RZfR5hDsDjoPJWm ojN4Mg >. Acesso em: 14.mar.2015

KINCHELOE, J. L. O poder da bricolagem: ampliando os métodos de pesquisa. In: ; BERRY, K. Pesquisa em educação - conceituando a bricolagem. Porto Alegre: Artmed, 2007, pp.15-37.

MARTINS, Raimundo; TOURINHO, Irene. Entre itinerários, conexões e perspectivas. In: MARTINS, Raimundo; TOURINHO, Irene. (Orgs.). Educação da cultura visual. Santa Maria: Ed. da UFSM, 2011, p. 7-9.

MASCAREllO, F. História do Cinema Mundial (Org.). Campinas/SP: Papirus, 2009, $432 \mathrm{p}$. 
OLIVEIRA, Marilda Oliveira de. O que pode um diário de aula? In: MARTINS, Raimundo; TOURINHO, Irene. (Orgs.). Processos e práticas de pesquisa em cultura visual e educação. Santa Maria: Ed. da UFSM, 2013, p. 225-236.

OLIVEIRA, Marilda Oliveira de. Por uma abordagem narrativa e autobiográfica: diários de aula como foco de investigação. In: MARTINS, Raimundo; TOURINHO, Irene. (Orgs.). Educação da Cultura Visual: conceitos e contextos. Santa Maria: Ed. da UFSM, 2011, p. 175-190.

PERUZZO, C. M. K. Tópicos sobre o ensino da Comunicação no Brasil. In:

SILVA, R. B. (Orgs.). Retrato do ensino em Comunicação no Brasil. São Paulo: Intercom, Taubaté: Unitau, 2003, pp. 119-138.

RANCIÈRE, J. O mestre ignorante - cinco lições sobre a emancipação intelectual. Belo Horizonte/MG: Autêntica, 2002, 143p.

SATLER, L. L. O Ensino da Publicidade entre o Passado e o Presente. In: TRINDADE, E.; PEREZ, C. (Orgs.). Há momentos em que precisamos parar: parar para pensar os rumos da publicidade contemporânea. Salto, SP: Editora Schoba, 2010, pp. 773-784.

SATLER, L.L.; MARTINS, A. F. Sai da caixa: o início de uma aventura emancipatória com o ensino audiovisual. In: GERALDO, S. C.; COSTA, L. C. (Orgs.). ENCONTRO DA ASSOCIAÇÃO NACIONAL DE PESQUISADORES EM ARTES PLÁSTICAS, 220, 2012a. Sai da caixa: o início de uma aventura emancipatória com o ensino audiovisual. Rio de Janeiro: ANPAP, 2012a.

SCHNetZler, R. P. Prefácio. In: GERALDi, C.M.G.; FIORENTINI, D.; PEREIRA, E. M. A. (Orgs.). Cartografias do trabalho docente: professor(a)-pesquisador(a). Campinas, SP: Mercado das Letras: Associação de Leitura do Brasil ALB, 1998, pp.7-10.

\footnotetext{
i É doutora em Artes e Cultura Visual (FAV / UFG), cursa pós-doutorado no Programa Avançado em Cultura Contemporânea (PACC/ UFRJ). Professora de Audiovisual na Faculdade de Informação e Comunicação (FIC/UFG).

Enviado em: 29 de outubro de 2016.
}

Aprovado em: 19 de novembro de 2016.

Revista Digital do LAV - Santa Maria - vol. 9, n. 3, p. 35 - 59 - set./dez. 2016 ISSN 1983 - 7348 http://dx.doi.org/10.5902/1983734824180 